\title{
Public health models for the future
}

Dr. Beaglehole is a public health adviser in the Department of Health Service Provision at WHO, Geneva with responsibility for strengthening public health capacity in low and middle income countries. He is on leave from his position as professor of Community Health, University of Auckland

In 1926 Winslow, a leading figure in public health in the USA in the first half of the last century, suggested that public health was at a turning point (Winslow 1999). The adverse effects of the industrialisation of the northern states on population health had been controlled in the last quarter of the $19^{\text {th }}$ century by the application of the sciences of sanitary engineering and bacteriology. Life expectancy in New York increased by almost 17 years from 36 years in the 40-year period up to 1920, largely due to the reduction in communicable disease mortality.

Winslow provided one of the earliest formulations of what we now know as the epidemiological transition (Omran 2001). The emergence of noncommunicable disease as the leading cause of death led Winslow to declare that public health was at a crossroads. He concluded that the main challenge facing public health was "the application of medical knowledge to the individual patient at a time when that knowledge can really exert a maximum effect". Winslow advocated the secondary prevention approach to chronic diseases based on their early detection and management when effective treatment might still be possible. He was also an early advocate for a national community-based health service - still a long way off in the USA.

Public health is again said to be at a crossroads (Beaglehole \& Bonita 1997). An important question now is whether public health practitioners took the best path 80 years ago. Two even more important questions arise: Are we on the right path now? And are the public health infrastructure and workforce strong enough to take advantage of current opportunities for collective action to advance the health of entire populations (Beaglehole 2003)? In hindsight, Winslow and colleagues did not set us off in the right direction; for one thing, the knowledge base for effective therapeutic interventions for chronic disease was almost non-existent, as was the evidence concerning the environmental determinants of the chronic disease epidemics. Winslow had misplaced confidence in the power of early detection and treatment and not enough confidence to explore alternative and more fundamental strategies for the prevention of the epidemics of chronic diseases. The epidemic of coronary heart disease did not reach its peak in the USA until the late 1960 and since then there has been a dramatic decline in mortality rates with another astonishing increase in life expectancy (Beaglehole 1999). The evidence base for effective interventions for chronic diseases - both therapeutic and preventive - has increased enormously, but only over the last two decades (Yusuf 2002). This knowledge gain undoubtedly contributed to the control of many of the leading causes of adult mortality, especially among the more privileged sections of the wealthy countries (Lawlor et al. 2003). However, the secondary prevention strategy will never control the underlying causes of the epidemics and must be complemented by the population-wide approach (Rose 1992).

This brief historical review illustrates the importance of the paper in this issue by Ansari and colleagues. The authors are epidemiologists working for a Department of Health in an Australian State so they are likely to be concerned with practical epidemiological matters, despite the great complexity of the associations under discussion. They argue that the practice of epidemiology should be guided by a theoretical framework which includes a leading role for the broad social determinants of health but also recognises the interconnectedness of these factors with others operating primarily at the level of the individual. Their public health model includes socio-economic determinants, psychosocial risk factors, and community and societal characteristics; it is proposed in the spirit of Susser and his paradigm of eco-epidemiology (Susser \& Susser 1996). Many other models have

Soz.- Präventivmed. 48 (2003) 214-215 
been proposed; perhaps the best known is the Canadian population health model (Evans \& Stoddart 1990), which has recently been re-evaluated by its authors (Evans \& Stoddart 2003).

The recognition of the importance of the socio-economic determinants of health is one of the "big ideas" of recent epidemiological endeavour. Two others are the influence of income inequality on population health status and the newer concept of social capital. Although these ideas have stimulated much research and debate, neither have yet had much impact on health policies and programmes (Mackenback 2002; Pearce \& Davey Smith 2003). The key challenge now for the advocates of the various models of the determinants of health is to show that they help public health scientists identify specific policies which improve the health of popu- lations and especially the health of the most deprived groups. This remains a fertile area for research; there is for example, little evidence that the Canadian model has led to the development of policies and programmes that have had beneficial health effects (Evans \& Stoddart 2003). Epidemiologists need to work together to research the various elements of these models with a view to identifying causal pathways which are amenable to politically acceptable interventions. If this process can be advanced, it will make a major contribution to the healthy development of epidemiology. In turn, this will contribute to an important redirection for public health away from the route signalled by Winslow.

Robert Beaglehole

\author{
References \\ Beaglehole R (1999). International trends in \\ coronary heart disease mortality and incidence \\ rates. J Cardiovasc Risk 6: 63-8. \\ Beaglehole R, ed. (2003). Global public health: a \\ new era. Oxford: Oxford University Press. \\ Beaglehole R, Bonita R (1997). Public health at \\ the crossroads. Cambridge: Cambridge Univer- \\ sity Press. \\ Evans RG, Stoddart GL (1990). Producing \\ health, consuming health care. Soc Sci Med 31: \\ 1347-63. \\ Evans RG, Stoddart GL (2003). Consuming rese- \\ arch, producing policy? Am J Public Health 93: \\ 371-9.
}

Lawlor DA, Frankel S, Shaw M, et al. (2003) Smoking and ill health: does lay epidemiology explain the failure of smoking cessation programs among deprived populations? Am J Public Health 93: 266-70.

Mackenback JP (2002). Income inequality and population health. BMJ 324: 1-2.

Omran AR (2001). The epidemiologic transition: a theory of the epidemiology of population change. Milbank Mem Fund Q 1971; 49: 509-38. Reprint. Bull WHO 79: 161-70.

Pearce N, Davey Smith G (2003). Is social capital the key to inequalities in health? Am J Public Health 93: 122-9.

Rose G (1992). Strategy of preventive medicine. Oxford: Oxford University Press.

Susser M, Susser E (1996). Choosing a future for epidemiology. 2, From black box to Chinese boxes and eco-epidemiology. Am J Public Health 86: 674-7.
Winslow C-EA (1999). Public health at the crossroads. Am J Public Health 1926; 16: 1075-85. Reprint. Am J Public Health 89: 1645-8.

Yusuf S (2002). Two decades of progress in preventing vascular disease. Lancet 360:2-3.

Address for correspondence

Dr. Robert Beaglehole

Department of Health Service Provision WHO

20, Avenue Appia

CH-1211 Geneva 27

Tel.: +41 22 7912508

Fax: +41 22 7914747

e-mail: beagleholer@who.int 